\title{
Milk fluoridation for the prevention of dental caries
}

\begin{abstract}
Jolán Bánóczy ${ }^{1}$, Andrew Rugg-Gunn², Margaret Woodward ${ }^{3 *}$
${ }^{1}$ Department of Oral Biology, Semmelweis University, Budapest, Hungary

${ }^{2}$ School of Dental Sciences, Newcastle University, UK

${ }^{3}$ The Borrow Foundation, Padnell Road Waterlooville, Portsmouth, UK

Corresponding author: Jolán Bánóczy

Semmelweis University of Medicine

Department of Oral Biology

Nagyvárad ter 4

1089 Budapest

Hungary

banoczy.jolan@dent.semmelweis-univ.hu

Tel.: + 3613032436

Fax.: + 3613032436

Received: 2 November 2012

Accepted: 29 January 2013

Copyright (c) 2013 by

Academy of Sciences and Arts

The aim of this review is to give an overview of 55 years experience of milk fluoridation and draw conclusions about the applicability of the method. Fluoridated milk was first investigated in the early 1950s, almost simultaneously in Switzerland, the USA and Japan. Stimulated by the favourable results obtained from these early studies, the establishment of The Borrow Dental Milk Foundation (subsequently The Borrow Foundation) in England gave an excellent opportunity for further research, both clinical and non-clinical, and a productive collaboration with the World Health Organization which began in the early 1980s. Numerous peer-reviewed publications in international journals showed clearly the bioavailability of fluoride in various types of milk. Clinical trials were initiated in the 1980s - some of these can be classed as randomised controlled trials, while most of the clinical studies were community preventive programmes. Conclusion. These evaluations showed clearly that the optimal daily intake of fluoride in milk is effective in preventing dental caries. The amount of fluoride added to milk depends on background fluoride exposure and age of the children: commonly in the range 0.5 to $1.0 \mathrm{mg}$ per day. An advantage of the method is that a precise amount of fluoride can be delivered under controlled conditions. The cost of milk fluoridation programmes is low, about $€ 2$ to 3 per child per year. Fluoridation of milk can be recommended as a caries preventive measure where the fluoride concentration in drinking water is suboptimal, caries experience in children is significant, and there is an existing school milk programme.
\end{abstract}

of Bosnia and Herzegovina.

E-mail for permission to publish:

amabih@anubih.ba
Key words: Caries prevention, Fluoride prevention, Milk fluoridation, Caries reduction, Community programmes.

\section{Introduction}

The aim of this article is to describe the history of milk fluoridation and its place in caries prevention. Individual studies have not been referenced in this review as they are listed in the WHO publication 'Milk fluoridation for the prevention of dental caries' (1).

\section{Early investigations into fluoridated milk}

The idea of milk fluoridation emerged, at about the same time, in Japan (1952), in Switzerland (1953) and the USA (1955). Early investigations showed that fluoride added to milk does not change its taste or other characteristics, is absorbed well, although slower

\footnotetext{
* The first two authors are trustees of The Borrow Foundation (Waterlooville, UK) and the third is employed by the organisation as the programme coordinator.
} 
than from fluoridated water. It was considered advantageous that fluoride is added to an important food for infants and small children, and that consumption of fluoridated milk is not mandatory for everybody, only for those who need it most and agree to receive it. The caries preventive effect of fluoride can even be enhanced by the milk vehicle, due to the cariostatic properties of the mineral, protein and fat content of milk.

The first clinical results were reported by Imamura in 1959, after a five-year study of Yokohama schoolchildren. Milk or soup, containing 2.0 to $2.5 \mathrm{mg}$ sodium fluoride, was consumed at lunch-time, 150 to 180 days per year, by 167 children. Compared with the control group, 29 to $34 \%$ caries reductions were observed in the permanent dentition. In Baton Rouge, Louisiana, USA, Rusoff and co-workers reported in 1962 on 3.5 years' results in 129 (65 test and 64 control) children. In children consuming fluoridated milk at school meals, 35\% less caries was recorded than in the control children; in those who were 6 years old at the beginning, the reduction was even larger at $70 \%$. In Winterthur, Switzerland, Ziegler and Wirz reported a study where $0.22 \%$ sodium fluoride solution, prepared by pharmacies in plastic bottles, was added by the parents within the home to milk consumed by children. Participants were 749 test and 553 control children who were 9 to 44 months old at the start of the programme. In 1964, after six years, caries reductions were $17 \%$ for the deft index (number of decayed, extracted or filled primary teeth) and $30 \%$ for the defs index (number of decayed, extracted or filled primary tooth surfaces) in the primary dentition, and $64 \%$ for DMFT (number of decayed, missing or filled permanent teeth) and 65 for DMFS (number of decayed, missing or filled permanent tooth surfaces) in permanent molars. The proportion of caries-free children increased significantly in the fluoridated milk group.

\section{The Borrow Foundation}

The establishment of a charity in England by Edgar Wilfred Borrow (1902-1990) for the promotion of milk fluoridation in order to prevent dental caries in children, brought important progress in the field of research and clinical studies. E.W. Borrow (Figure 1), a wealthy farmer and mechanical engineer in south England, constantly interested in the technical aspects of fluoridation of milk, set up a charity in 1971, named the "Borrow Dental Milk Foundation", for the above purposes.

The aims, summarized in 12 points, were mainly "to promote and support research of fluoridated milk for human consumption by the help of grants, equipment, lectures, scientific publications, and to disseminate knowledge about this method". The aims of the original 'Trustees' deed' were extended in 1993 to include "the support of activities on health promotion and education,... and on healthy nutrition, including milk and milk products".

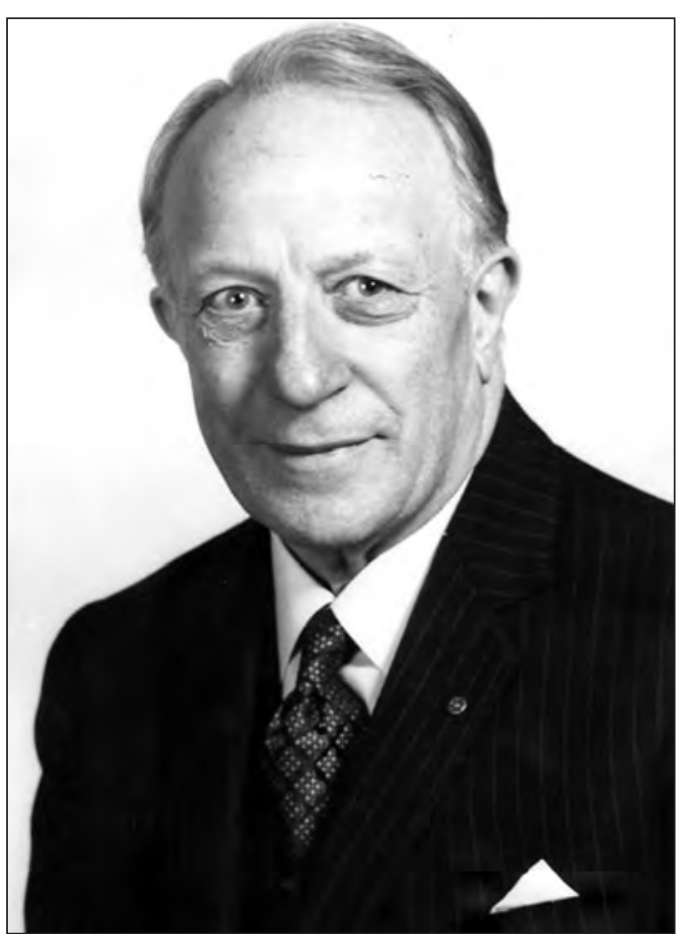

Figure 1 Edgar Wilfred Borrow - the founder of "The Borrow Foundation". 
The name of the foundation was changed in 2002 to 'The Borrow Foundation' (www.borrowfoundation.org). In recognition of his humanitarian services, E.W. Borrow received an Honorary Doctorate from Lousiana University, USA, in 1983. Two of the authors of this present review are two of the five "Trustees" of The Borrow Foundation.

The results of clinical and basic research studies, supported by The Borrow Foundation, have made the creation and extension of milk fluoridation programmes possible in numerous countries of the world. Based on discussions initiated in the 1980s between The Borrow Foundation and the World Health Organization (WHO), the Bulgarian milk fluoridation programme was initiated, and a 'Memorandum of Understanding' was signed by The Foundation and WHO in 1991; this has been renewed every three years. As a result of this collaboration, a book was published in 1996 (2), summarizing the studies of basic and clinical research into milk fluoridation, and a revised edition was published in 2009 (1).

\section{Theoretical considerations}

Concerning the pathomechanism of fluorides, it is accepted that elevated fluoride ion concentrations at the dental plaque/enamel border decrease the rate of demineralisation, increase remineralisation, and reduce acid production of dental plaque. However, the use of milk as a vehicle, generated questions concerning possible chemical reactions between milk and fluoride ions, bioavailability of systematically administered fluoride in milk, and interactions involving fluoride in the oral cavity (enamel, saliva, plaque and caries).

The results of basic studies on milk fluoridation have been published in more than 100 peer-reviewed papers, with increasing frequency in the last 20 years. Based on these studies, according to recent knowledge, the greater part of fluoride added to milk, forms a soluble complex with the protein fraction of milk, from which the fluoride can be liberated in ionic form, so that it is bioavailable. The absorption of fluorides with simultaneous food consumption is slower than for fluoride without food, and the proportion absorbed depends on the calcium content of the diet. Different types of milk are drunk in communities around the world - whole milk or low-fat milk, fresh, pasteurised or sterilised milk, liquid or dried milk. The bioavailability of added fluoride has been investigated in all of these, on the day of milk processing and after several days' storage, and shown to be satisfactory.

Because urine is the main vehicle for excretion of fluoride, analysis of 24 hour urine excretion is presently the best marker of fluoride intake (3). Recording of fluoride excretion in urine over 24 hours has been recommended before and after introduction of fluoridebased community preventive programmes. A WHO document, published in 1999, offers detailed guidelines for the method and calculations: based on these, the optimal fluoride concentration in milk and the appropriate intake of fluoride can be determined.

The systemic effect of fluorides in milk is supported by numerous experimental data. However, by the 1980s, the opinion as to how fluoride acts to prevent dental caries was going through a change: even with the use of systemic fluoride agents, topical effects were considered more important. The consumption of fluoridated milk incorporated into dental enamel inhibited demineralisation and promoted remineralisation. In addition, 30-60 minutes after ingestion of fluoridated milk, both the levels of fluoride in whole saliva and dental plaque increase as a consequence of the presence of fluoridated milk in the mouth and increased concentrations of fluoride in salivary secretions following the absorption of ingested fluoride. Thus, fluoride in milk acts both systemically and topically, in the same way as fluoride in water. 


\section{Clinical evaluations}

Long-term human studies with fluoridated milk on children, undertaken in about twelve countries have been reported in numerous peer-reviewed papers. Only some of these studies can be classified as RCTs (randomised controlled trials) according to the criteria used in evidence-based medicine; the others can be classed as community-based programmes. In the following paragraphs, the main features of the evaluations of these milk fluoridation programmes in different countries of the world will be summarized, but without the detailed numerical results which can be found in the relevant literature $(1,4,5)$ (Table 1$)$.

\section{Scotland: Glasgow}

Due to the strong criticism of the early clinical studies (for example, small numbers of participants, lack of baseline examinations, etc.), Stephen and colleagues initiated in Glasgow in 1976, a double blind clinical trial on $4 \frac{1}{2}$ and $5 \frac{1}{2}$ year old schoolchildren. The group of test children consumed $200 \mathrm{ml}$ milk each school day (about 200 days per year), containing $1.5 \mathrm{mg}$ fluoride, while the control group received plain milk. The results published in 1984, after five years, reported a $36 \%$ reduction in DMFT and a $48 \%$ reduction in DMFS values for the first permanent molars which were not yet erupted at baseline in the test group compared with the control group. Fluoride excretion in urine was monitored constantly during the study. (1) This evaluation (together with the Volgograd programme by Maslak: see later) is one of the programmes accepted as an RCT by the Cochrane Centre for Systematic Reviews.

Table 1 List of published reports of studies into the effectiveness of milk fluoridation

\begin{tabular}{lllll}
\hline & & & Caries prevention in: \\
\cline { 3 - 5 } Study & Year of study & Authors & $\begin{array}{l}\text { Primary } \\
\text { teeth }\end{array}$ & $\begin{array}{c}\text { Permanent } \\
\text { teeth }\end{array}$ \\
\hline Yokohama, Japan & $1952-1956$ & Imamura, 1959 & - & + \\
Baton Rouge, USA & $1955-1959$ & Rusoff et al., 1962 & - & + \\
Winterthur, Switzerland & $1958-1964$ & Wirz, 1964; Ziegler, 1964 & + & + \\
Agudos, Brazil & $1976-1979$ & Lopes et al., 1984 & - & - \\
Glasgow, UK & $1976-1981$ & Stephen et al, 1981; Stephen et al., 1984 & - & + \\
Fót, Hungary & $1979-1990$ & Bánóczy et al., 1983; Bánóczy et al., 1985; & & + \\
Louisiana, USA & $1982-1985$ & Legett et al., 1987 & + & + \\
Bethlehem, Israel & $1983-1986$ & Zahlaka et al., 1987 & - & + \\
Asenovgrad, Bulgaria & $1988-1993$ & Pakhomov et al., 1995; Atanassov et al., 1999 & + & + \\
Codegua, Chile & $1994-1999$ & Mariño et al., 2001 & + & + \\
Voronezh, Russia & $1994-2004$ & Pakhomov et al., 2005 & + \\
Wirral, UK & $1995-2003$ & Riley et al., 2005 & + \\
Beijing, China & $1997-1999$ & Bian et al., 2003 & - & - \\
Knowsley, UK & $1997-2001$ & Ketley et al., 2003 & + \\
Volgograd, Russia & $1998-2002$ & Maslak et al., 2004 & + \\
Araucania, Chile & $1999-2002$ & Weitz and Villa, 2004 & + \\
Umeå, Sweden & $2006-2007$ & Steckén-Blicks et al., 2009 & + \\
Ljungby, Sweden & $2006-2008$ & Petersson et al., 2011 & + \\
\hline
\end{tabular}




\section{Hungary: Fót}

In the 'Children's City' of Fót, a milk fluoridation programme was initiated by Bánóczy, Zimmermann and colleagues in 1979, involving about 1000 children aged 2 to 18 years (1). The results were published after 2, 3 and 10 years (1982-1992). The children drank for breakfast milk or cocoa, containing $0.4 \mathrm{mg}$ fluoride for kindergarten children and $0.75 \mathrm{mg}$ fluoride for the schoolchildren. The sodium fluoride solutions were prepared by the Pharmacy of Semmelweis University in closed glass bottles, then added to the milk in the kitchen of the home, stirred thoroughly for 15 minutes, and consumed within 30 minutes by the children. After five years, in the test group (165) children compared with a control group, a considerable caries reduction was observed in both the primary and permanent dentitions. In 7 to 10 year old children, these percentage reductions were 54\% in DMFT and 53\% in DMFS values. The reduction in the total permanent dentition was $60 \%$ for DMFT and $67 \%$ for DMFS; the highest reductions were found in the children who had consumed fluoridated milk from 2 to 3 years of age. The difference between the caries prevalence of the test and control groups was, in spite of loss of children from the study, still statistically significant after 10 years.

\section{USA: Lousiana, Baton Rouge}

In the second Lousiana community programme, begun in 1982, schoolchildren consumed fluoridated milk, containing cocoa and sugar, for lunch for two or three years. After two years, a significant caries reduction was observed in the permanent dentition: however, due to the loss of children, three year results could not be evaluated (1).The organiser of the experiment, Legett, planned also to establish a research institute for milk fluoridation which, however, could not be realised.

\section{Israel: Bethlehem}

Zahlaka and colleagues reported in 1987 the results of a study on 273 children who were aged 4 to 7 years at baseline and who had consumed fluoridated milk for three years. The fluoridated milk was produced from milk powder, and the dissolved milk contained 1 mg fluoride per litre. A 63\% caries reduction was observed in both the primary and permanent dentitions after three years (1).

\section{Bulgaria: Asenovgrad}

One of the most extensive milk fluoridation programmes was initiated by Pakhomov and colleagues in Bulgaria in 1988 with the support of WHO (1). The objective was to see if such a programme was feasible under everyday life conditions. Bulgaria seemed to be an excellent choice for this community-based programme due to the regular consumption of milk and milk products (for example, yoghurt) by children. The city Asenovgrad in south Bulgaria was selected as the test community and the nearby city of Panaguriche as the control community; later, Karlovo became the control community. The fluoridated milk was produced and transferred from the Plovdiv dairy, in plastic bags for each child containing $1 \mathrm{mg}$ fluoride per day. About 3,000 children aged 3 to 10 years entered the programme in Asenovgrad (Figure 2).

The caries examinations at baseline and after 3 and 5 years were performed by dentists calibrated by a WHO epidemiologist. Urine monitoring was carried out regularly. After five years, mean dmft values were 52\% lower in the test group children aged $6 \frac{1}{2}$ years and $40 \%$ lower in the $8 \frac{1}{2}$ year olds. The reductions in mean DMFT in these two age groups were $89 \%$ and $79 \%$ - statistically highly significant. After 10 years of the programme, Atanassov and colleagues recorded further significant differences in the proportion of caries-free children and in 


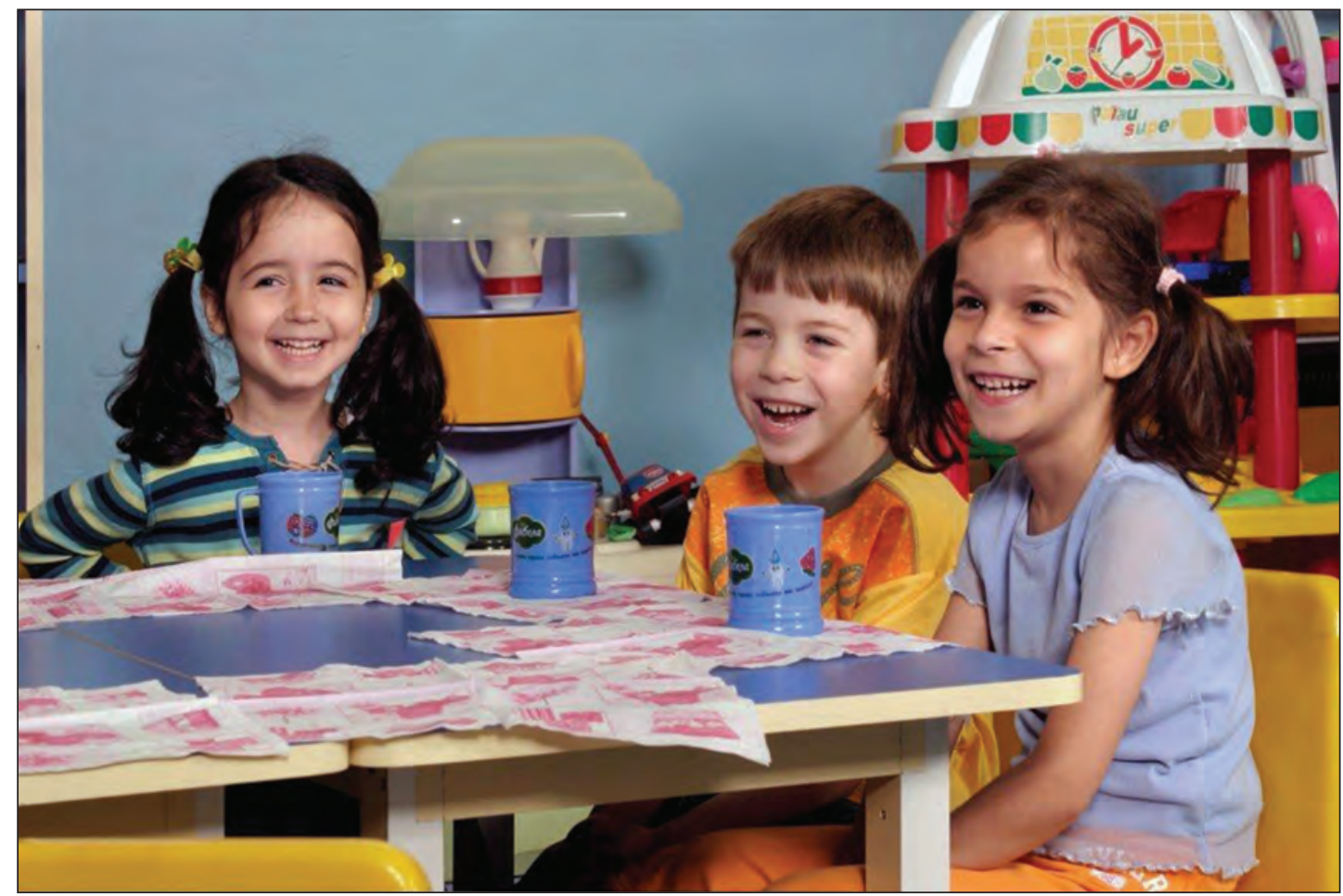

Figure 2 Bulgaria program: kindergarten children drinking fluoridated milk.

mean DMFT (1) values of the test and control groups. In some communities there is a preference for fluoridated yoghurt.

\section{Brazil and Peru}

From Agudos in Brazil, Lopes and colleagues reported in 1984 a small milk fluoridation study lasting 16 months. However, due to the short period, the results were not significant. In Peru, a milk fluoridation programme started in the early 2000s, based on the government programme 'vaso de leche', which provides one glass of milk for children each day. The programme was controlled by the University of Trujillo. The children received their milk in 'Mother's clubs', where a fluoride solution prepared by the pharmacies was added to fresh milk brought in by farmers, stirred thoroughly for 15 minutes, and consumed shortly after (1) (Figure 3 ).

However, the programme was stopped after a few years because of the expanding use of fluoridated salt in that community, before any evaluation was made. The encroachment of fluoridated salt was detect-

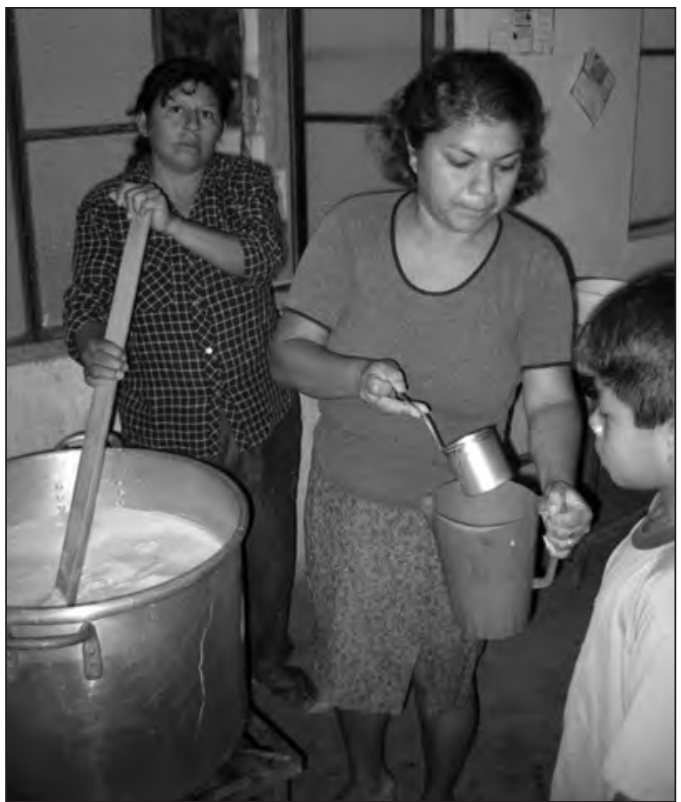

Figure 3 Peru program: fluoridated milk -after stirring- distributed at the "mothers club". 
ed before the community was aware of the presence of fluoridated salt, by monitoring of urinary fluoride excretion.

\section{Chile: Codegua and Araucania}

The Chilean milk fluoridation programmes possess two features which differ from other programmes. First, instead of using sodium fluoride they use sodium monofluorophosphate which, according to Villa and colleagues, has good bioavailability and other technical advantages and, second, the fluoride is added to powdered milk.

The first investigation took place in Codegua involving infants and young children, and took advantage of the 'national nutrition complementing programme' (PNAC) which has been in existence for more than 50 years. Under this scheme, every Chilean child, from birth to two years of age, receives two kilogrammes of milk powder every month, while children aged 2-6 years receive monthly one kilogramme of milk powder with cereals. The PNAC programme covers $90 \%$ of the child population. The fluoridated milk pilot programme was organised and evaluated by Villa, Mariño and colleagues in 1994 in the rural areas of Codegua (test) and La Punta (control). Children between 0 and 6 years of age consumed daily, for four years, $0.25,0.5$ or $0.75 \mathrm{mg}$ fluoride mixed into the milk powder, according to their age-group. Fluoride-containing toothpaste was available and urine monitoring for fluoride excretion was performed regularly. After five years, the proportion of caries-free children was higher in Codegua than in the control La Punta, and mean dmfs values showed significant reductions in children in Codegua compared with children in La Punta. However, examinations performed three years after cessation of the program showed very small differences, pointing to the necessity of continuous maintenance of caries preventive programmes.(1).
In the IXth region of Chile, a new fluoridated milk programme started in 1999 with about 35000 children aged 6 to 14 years who were participating in the national powdered milk programme (see above). In the community of Araucania, 6, 9 and 12 years old children received milk powder containing sodium monofluorophosphate, while the control children received milk powder without added fluoride. The control children were already participating in a community preventive programme in which they received applications of a high-fluoride gel. Examinations showed, historically, reductions in caries of 24 to $27 \%$ in children aged 9 and 12 years, which was similar to the results of the fluoride gel programme. Because the fluoride gel programme was difficult to administer (it involved gel application by health professionals), the milk-powder fluoridation programme has now been introduced into the majority of the Chilean regions as part of the caries preventive programme for 6-14 year old children living in rural communities. While the main cities in Chile receive optimally fluoridated water as a public health measure, milk fluoridation is provided in the rural areas where water fluoridation is technically not possible, in order to ensure equity.

\section{China: Beijing}

Due to the increasing caries prevalence in some parts of China, a milk fluoridation programme was introduced between 19941997 for Chinese kindergarten children in a district of Beijing. An evaluation showed no effect, probably due to the high amount of sugar (7-10\%) added to milk. In the second phase of the programme, therefore, no sugar or only small amount of sugar was added to the pasteurized milk which contained $2.5 \mathrm{ppm}$ fluoride and which was consumed everyday in kindergartens. In addition, children brought home fluoridated milk 
for weekends. Dentists calibrated to WHO standards examined the children after 21 months, recording also arrested caries. The mean $\mathrm{dmft}$ value in the test group showed a $69 \%$ reduction compared with the control (1). These results showed that fluoridated milk, when consumed daily, was able to prevent caries in the primary dentition and stop active dentinal caries from progressing, probably due to the topical effect of fluoridated milk. The study may also indicate the importance of not adding sucrose to milk (or other drinks).

\section{United Kingdom: Knowsley and Wirral}

A milk fluoridation programme was launched in 1997 in Knowsley by Ketley and colleagues, where 4060 three to five year old children (mean age 4.7 years), consumed, each day, milk containing $0.5 \mathrm{mg}$ fluoride; the control children in Skelmersdale drank plain milk. The number of days the children received milk was about 180 days per year. Caries evaluation was made, based on BASCD (British Association for the Study of Community Dentistry) criteria. After four years, no statistically significant differences in $\mathrm{dmft}$ and $\mathrm{dmfs}$ values of the two groups were found. The DMFT and DFS values were slightly, but not statistically significantly, smaller in the 7 to 9 year old children of the test group, than in the control. The assumption for these results was that the dose of fluoride in the milk was too low and that the period of consumption was not long enough to show an effect.

In a second evaluation in the Wirral region of north-west England, examinations, using the same BASCD criteria, were made by Riley and colleagues in 2003 on 5700 children who were at least 5 years old when they entered the fluoridated milk programme. Data for the four permanent molars were compared between 773 children who had been drinking fluoridated milk for six years at least, and 2052 children from Sefton, who had received milk without added fluoride. Caries prevalence in the test group was 13\% less in the primary dentition and $16 \%$ less in the permanent dentition. The mean DMFT value showed a reduction of $31 \%$, and the mean DFS a 37\% reduction, compared with the control (1).

\section{Russia: Volgograd and Voronezh}

Milk fluoridation programmes in Russia started in 1993 as a collaboration between the WHO and The Borrow Foundation, with participants initially in three communities Voronezh, Maykop and Smolensk - and later on in Volgograd and several communities in Tatarstan (Figure 4). Kouzmina and colleagues evaluated three year results in 1999 for 15000 participating children, and reported caries reductions between 55 and 68\%.

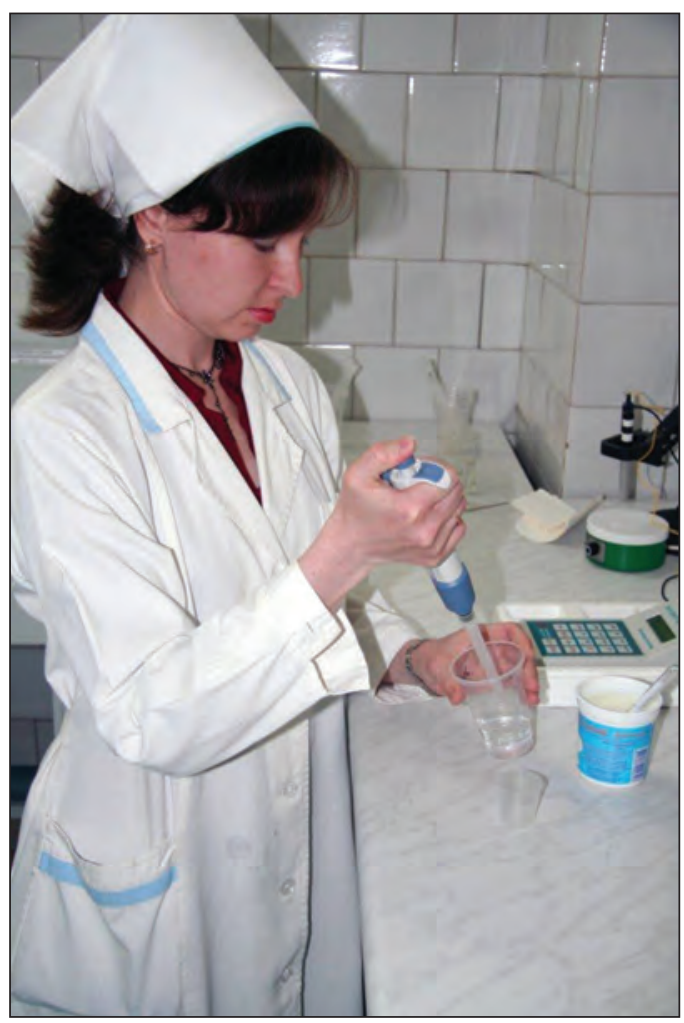

Figure 4 Measurement of the fluoride solution in the Russian program. 
The second milk fluoridation programme in Russia was in Volgograd, and this was evaluated by Maslak and colleagues in a three year study involving children who were caries-free when entering the programme at 3 years of age. In this doubleblind evaluation, undertaken by examiners calibrated according to WHO criteria, on 75 test and 91 control children, statistically significant reductions were recorded, both in dmft and DMFT values, and in longitudinal as well as cross-sectional comparative analyses. According to the evaluation by the Cochrane Centre for Systematic Reviews, this study, as well as that of Stephen and colleagues in Scotland, is accepted as an RCT and as evidence for the effectiveness of milk fluoridation.

In the town of Voronezh, the effect of a 10 year milk fluoridation programme was evaluated on 15000 kindergarten children in two horizontal comparative analyses. Pakhomov and colleagues compared data from 335 test and 175 control children after three years, and revealed a statistically significant reduction in $\mathrm{dmft}$ values and an increase in caries-free children in the test group. In a second analysis, data from 3, 6, 9 and 12 year old children were compared cross-sectionally with baseline data, and a statistically significant caries reduction was observed. Urinary fluoride monitoring showed that the daily consumption of $200 \mathrm{ml}$ milk containing $2.5 \mathrm{ppm}$ fluoride is an effective caries preventive method and that the fluoride intake corresponded to physiological norms (1).

\section{Thailand: Bangkok and other communities}

A well-organized milk fluoridation programme for children started in Thailand in the year 2000 with the help of The Royal Chitralada Projects a unique centre for agricultural and research development, initiated by His Royal Highness King Bhumibol Adulyadej. An evaluation is in progress. The

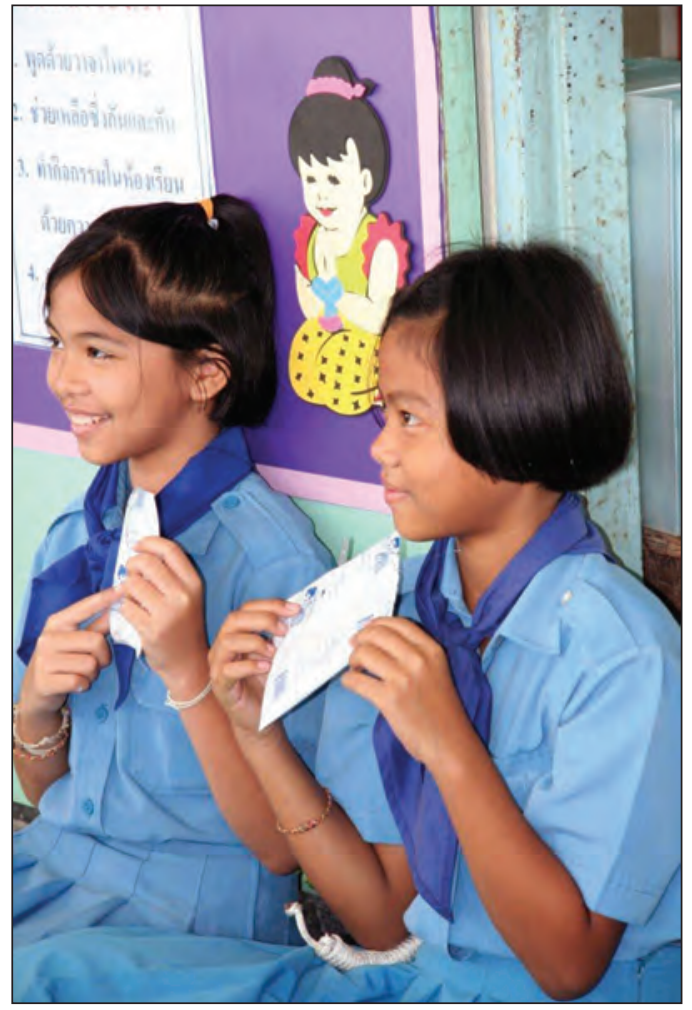

Figure 5 Thailand program: schoolchildren consuming fluoridated milk during a break.

project now includes all schoolchildren in Bangkok, and seven other provinces in Thailand, reaching nearly a million children in total (Figures 5 and 6).

\section{Former Yugoslav Republic of Macedonia}

In October 2009 the Ministry of Health introduced a milk fluoridation programme in the Former Yugoslav Republic of Macedonia which was promoted as one of the measures to be applied under a national strategy for prevention of oral diseases in children aged 0 to 14 years.

The scheme was established through the kindergarten system, and involved approximately 7,700 children aged 3 to 5 years, who received $200 \mathrm{ml}$ fluoridated UHT milk on school days. Although the programme ceased in 2011 when Government funding for school milk was decentralised to local 


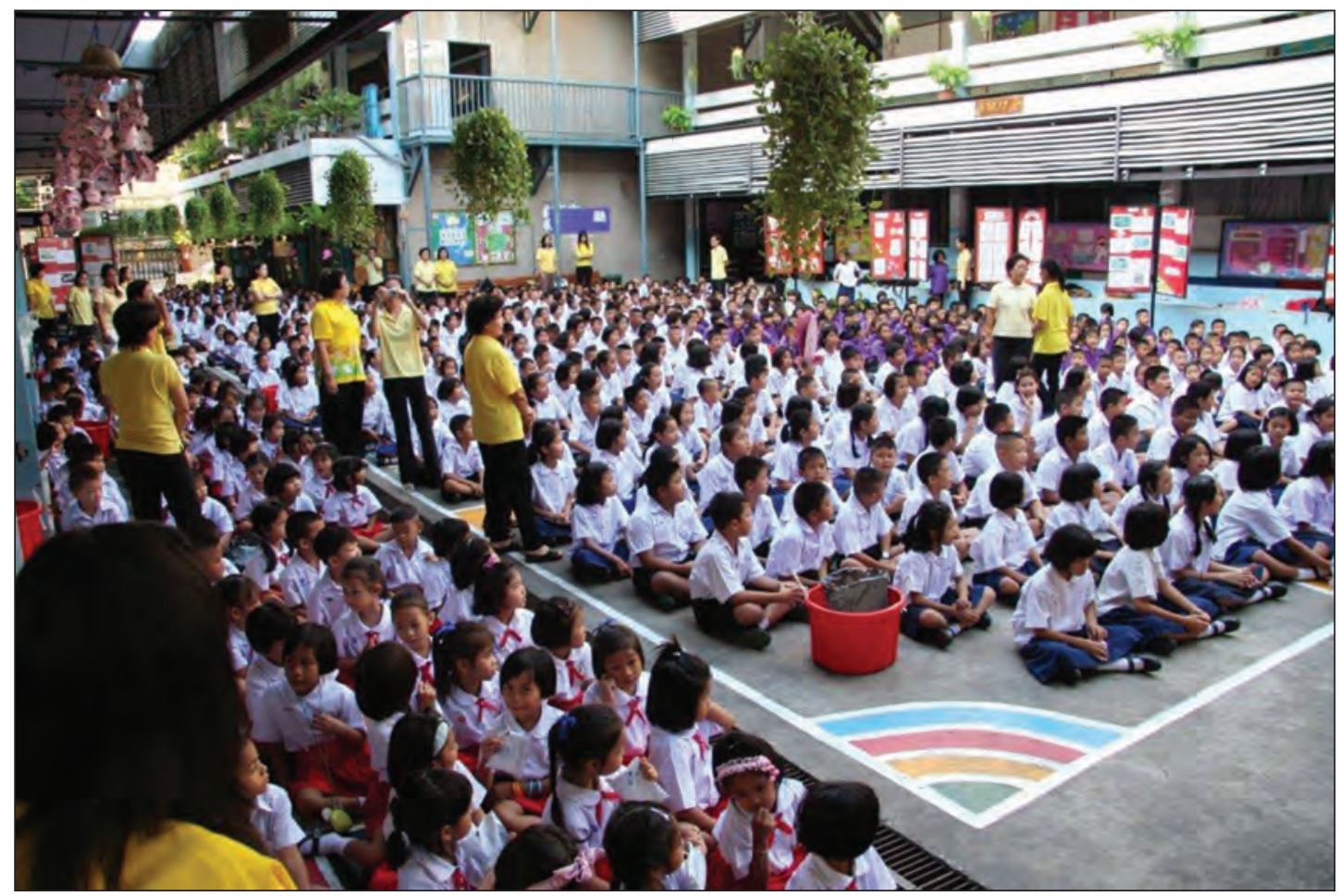

Figure 6 Thailand program: schoolchildren consuming fluoridated milk during a break.

municipalities, there is a will for the programme to be reinstated as part of a wider health promoting project, "Healthy Food for Healthy Childhood".

\section{Sweden: Umeå and Ljungby}

Stecksén-Blicks and colleagues (4) carried out an evaluation of the effect of supplementing milk with fluoride and probiotic bacteria which was provided to pre-school children in day care centres: the results were published in 2009. It was conducted near Umeå, northern Sweden, where there is a culture of using probiotics for general health benefits. 248 children aged 1 to 5 years attending 14 day care centres entered the study. The centres were randomly assigned to test and control. Children in the test group received $150 \mathrm{ml}$ of milk containing $2.5 \mathrm{mgF} /$ litre and probiotic bacteria while the control group received standard milk. The double-blind intervention lasted 21 months when a per cent caries reduction of $75 \%$ was recorded. Although there is some evidence elsewhere that probiotics confer some caries-preventive effect, the majority of this large effect is likely to be due to the addition of fluoride.

The second Swedish trial investigated prevention of dental caries in root surfaces of teeth in older people. The main outcome of this trial by Petersson and colleagues (5) and published in 2011, was the healing (remineralisation or hardening) of early lesions. Again, addition of fluoride and probiotic bacteria to milk was investigated but, unlike the Umea study, there were four parallel groups, so that the independent effects of fluoride and probiotics could be investigated. 160 healthy subjects aged 58 to 84 years took part: the study period was 15 months. The quantity of milk drunk was $200 \mathrm{ml}$ per day and the level of fluoride supplementation was $5.0 \mathrm{mg}$ F/litre. Although some benefit was recorded from consumption of probiotics, this effect was not statistically 
significant and the effect was much less than the statstically significant effect of fluoride.

\section{Safety considerations}

Numerous studies in several countries have demonstrated that ingestion of fluoride added to milk is well within WHO guidelines for young and older children: this conclusion is based on WHO guidelines for urinary fluoride excretion (6). One of the advantages of milk fluoridation is that a precise amount of fluoride is added to milk and provided to children each day. Follow up studies, by Mariño and colleagues (7), of children who took part in the Codegua study in Chile (see above) showed no adverse effect on the appearance of permanent front teeth which had been forming at the time the children were receiving their fluoridated milk.

\section{Cost of milk fluoridation programmes}

There have been several economic evaluations of the milk fluoridation programme in Chile $(8,9)$. These conclude that the programme costs about $€ 1.20$ to $€ 2.40$ per child per year. This figure is very similar to the figure of $£ 1.25$ (€1.50) per child per year in the UK milk fluoridation programme and
34.06 Thai baht (€ 0.86) per child per year in Thailand.

\section{Conclusions}

There are now over a million children receiving fluoridated milk (Table 2).

The effectiveness of milk fluoridation in preventing dental caries is supported by about 18 clinical studies reported in numerous papers. Of these, nine demonstrated caries prevention in primary teeth and 12 in the permanent dentition (Table 1). Two studies showed no effect in either dentition. An evaluation after cessation of a pilot milk fluoridation programme in Chile, caries incidence increased (10). Four RCTs showed caries reductions, and evaluations of the several community programmes pointed to the feasibility of the method under real life conditions. This evidence from clinical studies is underpinned by much research which demonstrates the bioavailibility of fluoride added to milk and the biological plausibility of milk fluoridation. Milk fluoridation is safe and the cost is low.

Based on these published studies, it seems that to obtain good results with milk fluoridation, even in the primary dentition, the programmes should start early, possibly

Table 2 The international programme

\begin{tabular}{llllll}
\hline Country & $\begin{array}{l}\text { Year F milk } \\
\text { programme } \\
\text { began }\end{array}$ & $\begin{array}{l}\text { Number of } \\
\text { participating } \\
\text { children }\end{array}$ & $\begin{array}{l}\text { Age-range } \\
\text { of children } \\
\text { (y) }\end{array}$ & $\begin{array}{l}\text { Amount of milk } \\
\text { (ml) }\end{array}$ & $\begin{array}{l}\text { Amount } \\
\text { of fluoride } \\
\text { (ml) }\end{array}$ \\
\hline Bulgaria* & 1988 & 31000 & 3 to 7 & 100 & 0.5 \\
& & & 200 & 0.75 \\
\hline United Kingdom & 1993 & 32000 & 3 to 11 & 189 & 0.5 \\
\hline Russian Federation & 1994 & 39000 & 3 to 11 & 200 & 0.5 \\
\hline Chile & 2000 & 220000 & 6 to 14 & 200 & 0.85 \\
\hline Thailand & 2000 & 982188 & 3 to 12 & 200 & 0.5 \\
\hline $\begin{array}{l}\text { Former Yugoslav Republic } \\
\text { of Macedonia† }\end{array}$ & 2009 & 7700 & 3 to 6 & 200 & 0.5 \\
\hline
\end{tabular}

*As at 2008; programme under review; †As at 2011; programme under review. 
before the age of four years. In order to protect the permanent molar teeth, consumption of fluoridated milk is necessary during and after their eruption too. The amount of fluoride added to milk is decided depending on age and background exposure to fluoride: the amount is commonly about $0.5 \mathrm{mg}$ per day for young children and around $1.0 \mathrm{mg}$ per day for older children. The introduction of milk fluoridation programmes should be considered where the fluoride content of drinking water is low, where a regular school milk system is working and where the children are able to consume the fluoridated milk for at least 200 days in a year.

Authors' contribution: Conception and design: JB and ARG; Acquisition, analysis and interpretation of data: ARG and MW; Drafting the article: ARG and MW; Revising it critically for important intellectual content: JB and AR.

Conflict of interest: The authors declare that they have no conflict of interest.

\section{References}

1. Bánóczy J, Petersen PE, Rugg-Gunn AJ, editors. Milk fluoridation for the prevention of dental caries. 2nd ed. Geneva: World Health Organization; 2009.

2. Stephen KW, Bánóczy J, Pakhomov GN, editors. Milk fluoridation for the prevention of dental caries. Geneva: World Health Organization/Borrow Dental Milk Foundation; 1996.

3. Rugg-Gunn AJ, Villa AE, Buzalaf MAR. Contemporary biological markers of exposure to fluoride.
In: Buzalaf MAR, editor. Fluoride and the oral environment. Monogr Oral Sci. Basel: Karger; 2011. p. 37-51.

4. Stecksén-Blicks C, Sjöström I, Twetman S. Effect of long-term consumption of milk supplemented with probiotic lactobacilli and fluoride on dental caries and general health in preschool children: a cluster-randomized study. Caries Res. 2009;43:374-81.

5. Petersson LG, Magnusson K, Hakestam U, Baigi A, Twetman S. Reversal of primary root caries lesions after daily intake of milk supplemented with fluoride and probiotic lactobacilli in older adults. Acta Odontol Scand. 2011;69:321-7.

6. Marthaler TM. Monitoring of renal fluoride excretion in community prevention programmes on oral health. Geneva: World Health Organization; 1999.

7. Mariño R, Villa A, Weitz A, Guerrero S. Prevalence of fluorosis in children aged 6-9 years-old who participated in a milk fluoridation programme in Codegua, Chile. Community Dent Health. 2003;20:143-8.

8. Mariño R, Morgan M, Weitz A, Villa A. The costeffectiveness of adding fluorides to milk-products distributed by the National Food Supplement Programme (PNAC) in rural areas of Chile. Community Dent Health. 2007;24:75-81.

9. Mariño R, Fajardo J, Morgan M. Economic evaluation of dental caries prevention programs using milk and its products as the vehicle for fluorides: cost versus benefits. In: Watson RR, Gerald JK, Preedy VR, editors. Nutrients, dietary supplements, and nutriceuticals: cost analysis versus clinical benefits. New York: Springer Science; 2011. p. 143-60.

10. Mariño RJ, Villa AE, Weitz A, Guerrero S. Caries prevalence in a rural Chilean community after cessation of a powdered milk fluoridation program. J Public Health Dent. 2004;64:101-5. 